\title{
ARTICLE
}

\section{How Can Our Human World Exist and Best Flourish Embedded in the Physical Universe? An Outline of a Problem-Based Liberal Studies Course}

\author{
Nicholas Maxwell \\ Department of Science \& Technology Studies, University College London
}

\begin{abstract}
In this paper I sketch a Liberal Studies Course designed to explore our fundamental problem of thought and life: How can our human world exist and best flourish embedded as it is in the physical universe? The fundamental character of this problem provides one with the opportunity to explore a wide range of issues. What does physics tell us about the universe and ourselves? How do we account for everything physics leaves out? How can living brains be conscious? If everything occurs in accordance with physical law, what becomes of free will? How does Darwin's theory of evolution contribute to the solution to the fundamental problem? What is the history of thought about this problem? What is of most value associated with human life? What kind of civilized world should we seek to help create? Why is the fundamental problem not a part of standard education in schools and universities? What are the most serious global problems confronting humanity? Can humanity learn to make progress towards as good a world as possible? These are some of the questions that can be tackled as an integral part of exploring the fundamental problem. But the Course does not merely wander at random from one issue to another. Taking the fundamental problem as central provides the Course with a coherent structure. The Course would be conducted as a seminar, and it would respond to queries and suggestions from students.
\end{abstract}

\section{Introduction}

In this paper I outline a Liberal Studies Course that is organized around the exploration of an open, unsolved, fundamental problem. Instead of providing answers to questions never stated or asked (as is so often the case in education), the Course explores imaginatively and critically, that is rationally, a real, unsolved, fundamental problem.

The basic problem of the Course can be stated quite simply like this:

Fundamental Problem: How can our human world - and the world of sentient life more generally - imbued with the experiential, consciousness, free will, meaning and value - exist and best flourish embedded as it is in the physical universe?

I interpret this fundamental problem in such a way that it encompasses all of academic thought, from theoretical physics, mathematics and cosmology, via the biological and technological sciences, to social inquiry and the humanities. It also encompasses literature,

$$
\text { Page } 36-->
$$

music and the other arts, politics, law, journalism, industry, agriculture and finance, and indeed all practical problems of living - problems facing individuals, groups, institutions, societies, nations, and humanity as a whole. It is, I suggest, our fundamental problem - our fundamental intellectual problem of knowledge and understanding, and our fundamental practical problem of living faced by each one of us personally in life, and faced by all of us 
together. ${ }^{1}$ A part of what the Course will attempt to do is see how this our fundamental problem connects up with more specific problems - problems of science, of social inquiry and the humanities, political and economic problems, problems each one of us face individually in life as we live - and problems that face humanity as a whole. The Course will attempt to trace out a kind of intellectual architecture of problems - from the allencompassing arch of the fundamental problem to the nooks and crannies of much more specialized research. The Course will also explore rival ideas as to what our fundamental problem is, how it should be formulated, and will attempt to assess the merits and demerits of these rival ideas.

Exploration of the fundamental problem will be a joint endeavour, shared by students and staff. The Course will consist of a series of discussion seminars.

\section{Youthful Questions and Education}

When we are young we endlessly ask questions. Why, why, why, we demand. Why is that dog barking? Why is the sky blue? What is electricity? Where did yesterday go? What is that bird doing? What are dreams? Why must we die? Then, education gets a hold of us, sits us down, tells us to shut up and listen. "You are here, not to ask questions, but to learn answers that we will teach you. We don't tell you what the questions were that led to these answers. We certainly don't allow you to think about the questions before telling you the answers. And we don't allow you to ask serious questions about what you are learning, and why you are learning it. Only when you have gone through a very long process of learning up an awful lot of answers may you, if you are very clever and persistent, be asked to follow up a very specialized question that we, the providers of education, have determined for your Ph.D."

Of course no teacher or lecturer at school or university ever says any such thing. It is just implicit in much that goes on at school and university. But doctrines never spoken that are implicit in everything that is spoken are all the more powerfully indoctrinating, just because the victim has no idea she is being indoctrinated, and so is unable to criticize and reject. It is, in any case, this doctrine, this educational practice of imparting answers without exploration of questions, this tyranny of answers-without-questions, that the Course wholly rejects. All the emphasis will be on the rational tackling of our fundamental problem.

As Einstein once said "It is, in fact, nothing short of a miracle that the modern methods of instruction have not yet entirely strangled the holy curiosity of inquiry; for this delicate little plant, aside from stimulation, stands mainly in need of freedom; without this it goes to wreck and ruin without fail". ${ }^{2}$ Consider what very young children manage to learn, without any kind of formal instruction, when given their freedom to do so, with plenty of stimulation. A child of three has, for herself, learned to understand a language and speak; she has created for herself a whole view of the world and a philosophy of life, a cosmology and some understanding of the social world she finds herself in. No wonder very young children are interested in philosophy: it is for them, as it is not so much for adults, a necessity, a matter of everyday practical learning and discovery. Furthermore, our three year old has learned how to act in the world, do things, manipulate spoons, dolls, cups and other utensils; and she has learned how to communicate and do things with others. And all this without a whisper of formal instruction of the kind she will soon receive in school. Compared with these mighty intellectual achievements, what Einstein did in creating relativity theory, or Darwin did in developing his theory of evolution, seem meagre indeed.

\footnotetext{
${ }^{1}$ For sustained exploration of this problem see Maxwell $(2001 ; 2010)$. For the argument that academic inquiry needs to sustain exploration of fundamental problems in order to be rigorous see Maxwell (1980). Most of my articles and Maxwell (2010) are available online at http://discovery.ucl.ac.uk/view/people/ANMAX22.date.html. If not available there, try http://philpapers.org/profile/17092.

${ }^{2}$ Einstein (1949, p. 17).
} 
Page 37 - - >

We then take these infant geniuses, these mighty intellectuals, these powerhouses of curiosity, discovery and imaginative invention, and we sit them down and tell them to shut up and listen to us. We patronize and humiliate them to an extent that is beyond belief. No wonder so many children become stupefied with boredom at school. What a miracle, indeed, it is that some fragments of the holy, delicate little plant of curiosity somehow survive in some of us, despite a decade or so of educational efforts to stamp it out. ${ }^{3}$

The problem-based Liberal Studies Course I am outlining swims against the tide. It is devoted to the exploration of our fundamental problem, in thought and in life, in the hope that this will stimulate curiosity, the desire to discover, to learn. The Course does not crush curiosity with endless unasked-for answers. Curiosity is stimulated with vistas of questions and problems - a whole intellectual cathedral of mystery. As the Course proceeds it is to be hoped that the astonishing wonder of this strange world around us, and within us too, will become all-too apparent.

\section{Is the Course Possible?}

"But does it make any kind of sense", it may be asked, "to expect undergraduates to survey and acquire an understanding of all of natural and technological science, all of social inquiry and the humanities, all of our global problems, in a mere three-year undergraduate Course? Only in Renaissance times was it possible for a very few mature geniuses to get a grasp of the entire culture. Nowadays no one can do it. And yet undergraduates, doing this Course, are expected to acquire such an overview of our whole vast, intricate, endlessly specialized culture in a mere three years. They are being asked to do the impossible!".

Each one of us, whoever we are, spend our lives in a state of supreme ignorance. Nevertheless we live in this world we only very partially and imperfectly know and understand. What really matters is that we have a sufficiently good, rough grasp of the whole to find our way around, aware of our ignorance but also able to learn what we need to learn, as and when it is needed or desired. We need a sympathetic interest in the diverse worthwhile endeavours of humanity, a sense of what theoretical physics at its best seeks to discover, an awareness of what great art or music achieves, some understanding of the good and the havoc that doctors, industrialists, politicians and bankers can do in the world. And in order to acquire these things, it is essential that we ourselves grapple, in a serious and sustained way, with our fundamental problems, the global problems that lie at the root of science, art, politics and life. If one has oneself thought long and hard about what kind of universe this may be then, however inadequate this thinking may have been, Newton, Faraday, Darwin, Einstein and all those other scientists become colleagues, friends and allies, assistants in one's own efforts to work things out, rather than authorities whose words must be accepted as final.

And besides, science is often made much more difficult than it need be - very much the view of Einstein, incidentally. Physicists often argue that, in order to understand physical theory it is essential to have the relevant mathematics at one's fingertips. Without it, all that will be available to one is more or less inadequate metaphors and analogies. But this is quite simply false - and perhaps reflects the inadequate understanding that some physicists have of their own discipline. One almost certainly needs to be a skilled mathematician in order to be able to derive empirical consequences from a physical theory - and of course if that is one's idea of what it is to understand a physical theory, then being an expert mathematician is indeed essential. But all that does is to reveal a pitifully inadequate grasp of what it is to understand a physical theory. The essential thing is to understand what it is

\footnotetext{
${ }^{3}$ For a proposal as to how education for young children might proceed so as to capitalize on childish questioning, see: Maxwell (2005b).
} 
that the theory asserts about the world at the theoretical level and not just at the empirical level. ${ }^{4}$

Take Einstein's theory of general relativity. Predicting phenomena from the theory is horrendously difficult. Nevertheless, even though one has not the faintest idea as to how that is to be done, one can still have an idea as to what the theory asserts about the world at the theoretical level. General relativity transforms gravity into an aspect of space-time. Space-time is four dimensional, three of space and one of time. Gravity, according to general

\section{Page 38- - >}

relativity, is nothing more than the curvature of space-time. Matter, or energy density more generally, tells space-time to curve; the curvature of space-time tells matter what path to travel along. Material objects (free of all forces except that of gravity) travel along geodesics - the nearest thing to straight lines in curved space-time. On the earth's two-dimensional curved surface, geodesics are great circles. What does it mean to say of a three or four dimensional space that it is curved? How do we tell whether it is curved or not? We draw a sufficiently large triangle in the space, and measure the angles of the triangle. If they equal $180^{\circ}$, the space is flat or Euclidean. If they add up to more than $180^{\circ}$, the curvature is positive, like that of the surface of a sphere (in two dimensions). If they add up to less than $180^{\circ}$, the space has negative curvature, like that of a saddle (in two dimensions). Actual physical space-time, according to general relativity, has variable curvature depending on how much mass, or energy density, is in the vicinity. There are even waves of variable curvature which travel through space at the speed of light.

Not a hint of mathematics, and yet we have before us the elements of what it is that general relativity asserts about the world. Mathematics is needed, of course, to extract empirical predictions from the theory, concerning such things as the orbits of the planets around the sun, the motions of double stars around each other, the formation and character of black holes.

Take any discipline: theoretical physics, anthropology, cosmology, evolutionary biology, history, geology, economics, mathematics, philosophy, genetics, English literature, organic chemistry, politics, linguistics, international affairs, neuroscience, human geography. What matters is that students doing the Course come to have some sympathetic understanding of what the basic problems and tasks of these disciplines are, some appreciation of the best of what has been achieved in each case, and what still needs to be done. It is to be hoped that the student will become aware of some of the technical difficulties confronting each discipline, so that he acquires some appreciation of what he does know and understand, and what he does not, knowledge and understanding fading into ignorance and incomprehension. It is to be hoped that the student will come to appreciate how each of these disciplines contributes to illuminating our understanding of the fundamental problem to which the Liberal Studies Course is devoted. It is to be hoped, too, that the special vantage point of the Course will enable the student to discern inadequacies in current specialist research, and would enable him eventually to put forward proposals as to how such specialist research can be improved so as to make more fruitful contributions to the fundamental problem. But all this would come in a secondary way, incidentally as it were, to

\footnotetext{
${ }^{4}$ Anyone inclined to think that knowing something about science has nothing to do with a liberal education should immediately find a copy of Karl Popper's masterpiece, The Open Society and Its Enemies, vol. 2, (Popper, 1962), and look up footnote 6 to chapter 11, pp. 283-284, where Popper argues passionately that science is vital to an authentic liberal education. He says "For science is not merely a collection of facts about electricity, etc.; it is one of the most important spiritual movements of our day. Anybody who does not attempt to acquire an understanding of this movement cuts himself off from the most remarkable development in the history of human affairs".
} 
the main task: to explore, with laughter and passion, with imagination and scepticism, our fundamental problem.

One immense advantage in giving priority to tackling our fundamental problem is that, as a result, the whole Course has a focus, a structure, a unity, a natural coherence. Take the fundamental problem away, and one is left with a disjointed jumble of specialized disciplines, one item after another, intricate answers to questions never posed, let alone explored. Not only is such a diet indigestible. Devoid of the problems that gave rise to these disciplines, these specialized answers, we are rendered incapable of assessing their adequacy, their rationality. Education degenerates into indoctrination.

\section{Why the Fundamental Problem is a Problem}

At this point it may be asked: "But this fundamental problem that the Course is supposed to tackle - the problem of how our human world can exist and flourish embedded in the physical universe: why is it such a problem? What exactly is the problem?"

Imagine you go for a walk in the countryside with a friend. It is early Summer. The sun is out, there are flowers in the meadows, a gentle breeze rustles the leaves of the trees overhead, white puffs of cloud drift across the blue sky, and you say to your friend "what a day to be alive!" She says "Yes!", and you stop for a picnic.

Page $39-->$

Now consider what physics tells us about this scene. Everything you have seen, heard, felt, experienced, thought disappears. You, your friend, the ground, grass, trees and leaves around you are made up of molecules, in turn made up of atoms, in turn made up of electrons, protons and neutrons, the latter two in turn made up of quarks and gluons (gluons being particles associated with the so-called strong force that glue quarks together). Sunlight is just electromagnetic waves or, if understood quantum mechanically, billions of particles of various energies called photons. Everything, in short, is just a vast conglomeration of just a very few different kinds of fundamental physical particles interacting with each other in accordance with the precise laws of physics. And this includes you and your friend, your brains, everything you say, experience, feel and think. When you say "What a day to be alive!" all that happens is that potassium and sodium ions are transmitted in waves down neurons in your brain, leading to muscles being contracted in your chest, tongue and mouth, causing air to vibrate your vocal chords which in turn cause molecules of the air to dart backwards and forwards in the form of a wave which travels through the air, and which, in turn, causes the ear drums of the ears of your friend to vibrate, in turn causing the little bones of the middle ear to vibrate, provoking in turn vibrations in the inner ear, picked up by tiny hairs which cause neurons to fire, transmitting neuron signals to the brain, which in turn lead to vibrations of the vocal chords and in the air corresponding to "Yes!". The green of the grass, the blue of the sky, the sound of your voices, the smells and tastes of the food of your picnic, your experiences of these things, your thoughts and feelings, your intention to speak, your friend understanding what you say, your mutual decision to stop for the picnic, the meaning and value of your walk in the countryside: all these vanish leaving bleak physics behind, fundamental particles interacting with one another in accordance with precise physical law. Even you and your friend disappear. For you to exist, you must be able to act in the world; you must be able to feel, think, experience, perceive, and initiate action, exercise free will. But in this world of physics, there is no room for free will; instead of thoughts, feelings, perceptions, decisions, acts of free will, there are just physical processes going on in your brain causing muscles to contract, your physical body to move around and, on occasions, emit noises - vibrations of molecules in the air. ${ }^{5}$

${ }^{5}$ The argument that physics cannot predict or explain the experiential is usually attributed to Nagel (1974) and Jackson (1982; 1986), although I first spelled out the argument some years earlier in Maxwell (1966; 1968a; 1968b): see especially Maxwell (1966, pp. 303-8; and 1968b, pp. 127 and 134-7). Decades later, in 1999, I wrote to Nagel and Jackson to ask 
This is the heart of the problem. How our human world, the world we experience, everything we hold precious and of value, can survive the corrosive acid of physics.

The problem is very, very old. It goes all the way back to Democritus, over two thousand years ago, one of the first to conceive of the world in purely physical terms. Democritus held that the universe is made up exclusively of indestructible atoms which move through the void. And he declared:

Colour exists by convention; sweet and sour exist by convention: atoms and the void alone exist in reality. ${ }^{6}$

Two thousand years later, in 1632, Galileo expresses a somewhat similar view:

these tastes, odours, colours, etc., so far as their objective existence is concerned, are nothing but mere names for something which resides exclusively in our sensitive body, so that if the perceiving creatures were removed, all of these qualities would be annihilated and abolished from existence. ${ }^{7}$

Galileo goes on to point out that if a feather tickles us we hold that the tickling is in us, not in the feather. In a similar way, colours, sounds and smells are a kind of tickling in us, and are not objective features of things external to us.

All the great natural philosophers associated with the birth of modern science - Descartes, Locke, Huygens, Newton and the others - agreed with Galileo. And most scientists today agree as well.

One approach to solving the problem is to adopt the view indicated by Democritus. Reality is such that physics is in principle capable of being correct and complete about everything. In the end, only the physical exists, and anything - such as the experiential - not capable of being even in principle reduced to physics does not really exist. It is just an illusion. ${ }^{8}$ But

Page $40-->$

can we really believe that everything we experience, everything that gives meaning and value to our lives - indeed our very existence as persons - is just an illusion?

Another possibility is that indicated by Galileo, and formulated clearly by Descartes. ${ }^{9}$ As far as the material world is concerned, physics is in principle capable of being correct and comprehensive. The material world consists exclusively of the physical. But in addition to the physical universe, there is the universe of conscious minds. Each living human brain has, associated with it, a non-physical mind. But this view, usually called Cartesian Dualism, faces horrendous problems. How can the mind and the brain interact? This is required if we are to be able to know anything about the world around us, and if we are to have free will. Can we really believe in the existence of Cartesian minds, distinct from but interacting with, brains? And does not this view suffer from the fatal flaw that if everything we experience is

them if they had come across my papers - and I sent copies. Nagel replied with great generosity "There is no justice. No, I was unaware of your papers, which made the central point before anyone else." Jackson admitted he had read my "Understanding Sensations". In his case, something close to plagiarism (of idea, not words) is involved. Some time later I met Jackson, and raised the matter with him. He said he had now abandoned what tends to be called "the knowledge argument". So, having taken credit for my work, he had now repudiated it!

6 A slightly different translation is quoted in Guthrie (1978, p. 440).

7 Galileo, The Assayer, quoted in Matthews (1989, pp. 56-57).

${ }^{8}$ For a modern exposition of the hardline physicalism of Democritus, see Smart (1966).

${ }^{9}$ Descartes (1949). 
in our minds, then it seems impossible that we should ever be able to know anything at all about the physical universe around us.

Another possibility is to deny the existence of the physical universe, declare everything to be in the mind, or made up of human experience, even physics in the end being about no more than actual or possible sense impressions. ${ }^{10}$ But can we really believe that this vast and ancient cosmos we seem to have discovered, made up of billions of galaxies, each made up of billions of stars, stretching for billions of light-years into the distance, some 14 billion years old at least, is all somehow in our minds? It does not seem credible. What science tells us, surely, is that human life is a minute and very recent phenomenon in this vast and ancient universe, mostly utterly alien to our human interests and desires.

Yet another possibility - and the one I favour - is that physics needs to be interpreted as being about only a highly selected aspect of everything: the causally efficacious aspect, as it may be called. The silence of physics about colours, sounds, and smells as we experience them, or our inner experiences of these things, is no reason whatsoever to hold that these things don't really exist, because physics is designed specifically to leave these experiential features out. They are not causally efficacious properties, as mass, or electric charge, are. Even if they exist, physics can leave them out because mention of them is not required to fulfil the predictive tasks of physics. Wavelength of light must be mentioned, but that this light is reddish can be ignored. And furthermore, it must be ignored. If physics sought to include the experiential, it would need to add to physical theory a great number of horribly complex additional postulates linking physical states of affairs with experiential qualities: colours, sounds and smells as we perceive them, and inner experiences. The beautifully unified and explanatory theories we have in physics - Newtonian theory, classical electrodynamics, quantum theory, general relativity, the standard model - would become horribly complex and disunified, and so non-explanatory. Leaving the experiential out of physics is the price we pay to develop the beautifully explanatory physical theories we have developed. Thus, the silence of physics about the experiential is no grounds whatsoever for supposing that the experiential does not really exist. We should believe in the evidence of our eyes, and hold that grass really is green, sky blue, roses red, out there in the world around us. ${ }^{11}$

Even if this fourth view is, broadly speaking, correct (and it may not be), there is still much that we do not know and understand. There are still immense mysteries before us. We don't understand how and why the experiential and the physical - or the neurological - are correlated in the way that they are. ${ }^{12}$ We don't even know how, or where, consciousness is located in the brain. Some of what goes on in the brain is consciousness, but much that goes on may support but is not, itself, consciousness. An absolutely elementary question, then, is simply: where in the brain is consciousness to be located? We do not really know. ${ }^{13}$ Nothing could highlight more dramatically our profound ignorance of ourselves - how what happens to the person and to the person's brain, are inter-related.

\section{Global Problems of Living}

So far I have hinted at some of the intellectual issues the Course will explore - problems that arise in connection with understanding how our human world exists embedded in the

Page $41-->$

physical universe. But this is only one aspect of our fundamental problem - and perhaps not the more fundamental aspect. There is also the problem of how what is of value in our human world can best flourish embedded as it is in the physical universe. What is of most

\footnotetext{
${ }^{10}$ Berkeley (1957).

${ }^{11}$ For expositions of aspects of this view see Maxwell (1966; 1968a; 1968b; 1984 or 2007a, ch. 10; 2000b; 2001; 2011a; and especially 2010).

${ }^{12}$ But see Maxwell (2011a).

${ }^{13}$ For a conjecture see Maxwell $(2001$, ch. 8).
} 
value in life? And how is it to be realized? What kind of ideal global society should we strive to achieve, in the long term? How do we achieve it? What do we need to do to make progress towards such a practical, ideal global society? How can academia help? What kind of academic inquiry would best help humanity learn how to make progress towards as good and wise a world as possible? These agonizing problems lie at the heart of the Liberal Studies Course.

Humanity is in a state of impending crisis. And the fault lies in part with academia. For two centuries or so, academia has been devoted to the pursuit of knowledge and technological know-how. This has enormously increased our power to act which has, in turn, brought us both all the great benefits of the modern world and the crises we now face. Modern science and technology have made possible modern industry and agriculture, the explosive growth of the world's population, modern armaments and the lethal character of modern warfare, destruction of natural habitats and rapid extinction of species, immense inequalities of wealth and power around the globe, pollution of earth, sea and air, even the aids epidemic (aids being spread by modern travel). Above all, the great success of modern science and technology have made possible our most serious threat of all, the impending disasters of climate change, which promise to intensify all our other global problems (apart, perhaps, from population growth which may fall off when millions, possibly billions, begin to die). All these global problems have arisen because some of us have acquired unprecedented powers to act, via science and technology, without also acquiring the capacity to act wisely. We urgently need a revolution in universities so that the basic intellectual aim becomes, not knowledge merely, but rather wisdom - wisdom being the capacity to realize what is of value in life, for oneself and others, thus including knowledge and technological know-how, but much else besides. This revolution would put problems of living at the heart of the academic enterprise, the pursuit of knowledge emerging out of, and feeding back into, the fundamental intellectual activity of proposing and critically assessing possible actions, policies, political programmes, from the standpoint of their capacity to help solve problems of living. This revolution would affect almost every branch and aspect of academic inquiry. ${ }^{14}$

\section{Aim-Oriented Rationality}

Einstein once put what is wrong in a nutshell like this: "Perfection of means and confusion of goals seem - in my opinion - to characterize our age." ${ }^{\text {All }}$ our global problems have arisen because, aided by science and technology, we have been able to pursue goals with immense success that seem, in the short term, highly desirable but which, in the long term, are disastrous. We urgently need to learn how to improve our aims and methods in life, at personal, social, institutional and global levels. And for that we need a new conception of rationality - aim-oriented rationality as I have called it ${ }^{16}$ - specifically designed to facilitate the improvement of problematic aims (the progressive resolution of problems associated with partly good, partly bad, aims). A central task for academia, for universities around the world, is to help people learn how to build aim-oriented rationality into personal and institutional life so that problematic aims may be progressively improved. Far from engaging in such a task, academia fails to put aim-oriented rationality into practice itself. It fails even to acknowledge or recognize the highly problematic character of its own aims, and the need to improve them. ${ }^{17}$

Even science fails to do this. The official view of the scientific community is that the basic intellectual aim of science is truth, the basic method being to assess claims to knowledge impartially with respect to evidence. But this is nonsense. In physics, only unified or

\footnotetext{
2012a; 2013b; 2014a; 2014b; 2014c).

${ }^{15}$ Einstein (1973, p. 337).

${ }^{16}$ Maxwell (1984 or 2007a, ch. 5).

${ }^{17}$ See works referred to in note 14.
}

${ }^{14}$ For a detailed exposition of this thesis and argument, see Maxwell (1984 or 2007a). See also Maxwell (1980; 1992; 2000a; 2003; 2004; 2007b; 2008a; 2008b; 2009a; 2009b; 
explanatory theories are ever accepted - or even considered. A theory, in order to be accepted, has to satisfy two requirements. It must be sufficiently empirically successful. And it must be sufficiently unified or explanatory in character. Endlessly many empirically more successful disunified rivals can always be concocted, but these are never considered for a

Page $42-->$

moment just because they are disunified. What this means is that the whole enterprise of theoretical physics (and therefore of natural science) just accepts, as a basic assumption, that some kind of unified pattern of physical law runs through all phenomena. The universe is, in some way, more or less physically comprehensible. The basic aim is not truth per se; it is, rather, unified truth, explanatory truth - truth presupposed to be unified or explanatory. But this real aim is far too problematic for the scientific community to acknowledge - because it involves acknowledging that science makes a big, highly problematic, metaphysical assumption: the universe is physically comprehensible. So it is repressed and denied. But the outcome of that denial is that this highly problematic aim - the highly problematic assumption inherent in the aim - cannot be subjected to sustained imaginative and critical discussion, as an integral part of science, to try to improve it. The aim of science does evolve over the centuries, of course, but not as a result of sustained critical discussion. ${ }^{18}$

And it does not stop there. The aim of discovering explanatory truth is just a special case of a more general and perhaps even more problematic aim of discovering valuable truth. And that is sought in order that it will be made available to people in life, ideally to enrich life, either via intellectual aspects of science, or its practical, technological aspects. Science, in other worlds, has social, humanitarian or political aims. All these aims, laden with metaphysics, values and politics, are deeply problematic, and need sustained imaginative and critical discussion, by scientists and non-scientists alike, if science is to be sensitively responsive to the real needs of humanity. But because of misrepresentations by the scientific community of the basic aims of science - because of firm allegiance to untenable orthodox views about science which hold that science appeals exclusively to evidence - the problematic aims of science are not subjected to sustained imaginative and critical attention, and do not steadily improve as a result. Science does not itself put aim-oriented rationality into practice. Academia more generally does not put aim-oriented rationality into practice. Neither are in a position to help humanity do this in social life. And humanity does not do it either - in politics, industry, agriculture, economic activity, finance, international relations, and so on. And the outcome of this almost universal neglect of the most elementary principles of reason (designed to help us improve problematic aims) is that the world is in the mess that it is in, with every prospect of things becoming very grim indeed in the not too distant future. ${ }^{19}$

\section{Conclusion}

These, then, are some of the issues to be explored in the problem-based Liberal Studies Course. There is a sense in which the Course will be doing philosophy, if by philosophy one means either (a) exploration of fundamental problems, or (b) exploration of aims and methods of diverse worthwhile but problematic endeavours - exploration of the philosophy of these endeavours, in other words. But academic philosophy today, on the whole, neglects scandalously to do either of these things, (a) or (b). Analytic philosophy is lost in ever more specialized, esoteric discussion of technical puzzles. And Continental philosophy continues to be turgid bombast. Both are forms of anti-philosophy. There is a sense in which this is what the world suffers from: the absence of intelligent philosophy devoted to sustained

${ }^{18}$ For detailed expositions of this thesis and argument concerning the aims and methods the philosophy - of science, see Maxwell (1974; 1984 or 2007a, ch. 9; 2005a; 2006; 2008a; 2010, ch. 5; 2011b; 2012b; and especially 1998; 2004; 2007a, ch. 14; and 2013b).

${ }^{19}$ See works referred to in note 14. 
rational exploration of fundamental problems, rational exploration of problematic aims, and associated methods, of major worthwhile but problematic social endeavours (with the aim of helping to improve them). ${ }^{20}$ It is in this sense of philosophy, vital but at present almost universally neglected and ignored, that the Liberal Studies Course is a Course in Philosophy.

\section{References}

Berkeley, G., 1957, A New Theory of Vision and other writings, Dent, London (first published 1709, 1710 and 1713).

Descartes. R., 1949, A Discourse on Method Etc., Dent, London (first published 1637).

Einstein, A., 1949, Autobiographical Notes, in P. A. Schilpp, ed., Albert Einstein:

Philosopher-Scientist, Open Court, La Salle. 1973, Ideas and Opinions, Souvenir Press, London.

Guthrie, W.K.C., 1978, A History of Greek Philosophy: Vol. II, The Presocratic Tradition from Parmenides to Democritus, Cambridge University Press, Cambridge.

Jackson, F., 1982, Epiphenomenal Qualia, Philosophical Quarterly 32, 127-136. 1986, What Mary didn't Know, Journal of Philosophy 83, 291-295.

Matthews, M.R., 1989, The Scientific Background to Modern Philosophy, Hackett, Indianapolis.

Maxwell, N., 1966, Physics and Common Sense, British Journal for the Philosophy of Science 16, pp. 295-311.

, 1968a, Can there be Necessary Connections between Successive Events?, British Journal for the Philosophy of Science, vol. 19, pp. 1-25.

127-146. 1968b, Understanding Sensations, Australasian Journal of Philosophy 46, pp.

1974, The Rationality of Scientific Discovery, Philosophy of Science, 41, pp. 123-

153 and 247-295.

1980, Science, Reason, Knowledge and Wisdom: A Critique of Specialism,

Inquiry, vol. 23, pp. 19-81.

1984, From Knowledge to Wisdom, Blackwell, Oxford.

1992, What Kind of Inquiry Can Best Help Us Create a Good World?, Science,

Technology and Human Values, vol. 17, pp. 205-27.

1993, Induction and Scientific Realism, British Journal for the Philosophy of

Science, vol. 44, pp. 61-79, 81-101 and 275-305.

, 1998, The Comprehensibility of the Universe: A New Conception of Science,

Oxford University Press, Oxford.

2000a, Can Humanity Learn to Become Civilized? The Crisis of Science without

Civilization', Journal of Applied Philosophy 17, pp. 29-44.

49-71.

2000b, The Mind-Body Problem and Explanatory Dualism, Philosophy, vol. 75, pp.

2001, The Human World in the Physical Universe: Consciousness, Free Will and

Evolution, Rowman and Littlefield, Lanham, Maryland. 2003, Do Philosophers Love Wisdom, The Philosophers' Magazine, Issue 22, $2^{\text {nd }}$

quarter, pp. 22-24. 2004, Is Science Neurotic?, Imperial College Press, London.

2005a, Popper, Kuhn, Lakatos and Aim-Oriented Empiricism, Philosophia, vol. 32,

nos. 1-4, pp. 181-239.

2005b, Philosophy Seminars for Five Year Olds', Learning for Democracy, vol. 1,

no. 2, pp. 71-77.

2006, Practical Certainty and Cosmological Conjectures, in Is there Certain

Knowledge?, ed. Michael Rahnfeld, Leipziger Universitätsverlag, Leibzig, 2006, pp. 44-59. 2007a, From Knowledge to Wisdom: A Revolution for Science and the Humanities,

Pentire Press, London (2nd revised and extended edition of Maxwell, 1984).

${ }^{20}$ See Maxwell (2003; 2008b; 2012a; 2013b; 2014b; and especially 2014c.) 
2007b, From Knowledge to Wisdom: The Need for an Academic Revolution,

London Review of Education, vol. 5, pp. 97-115, reprinted in. R. Barnett and N. Maxwell, eds., Wisdom in the University, Routledge, London, 2008, pp. 1-19.

2008a, Do We Need a Scientific Revolution?, Journal for Biological Physics and

Chemistry, vol. 8, no. 3, pp. 95-105.

2008b, Are Philosophers Responsible for Global Warming?, Philosophy Now, issue 65 , pp. 12-13.

, 2009a, How Can Life of Value Best Flourish in the Real World?, in Science and

the Pursuit of Wisdom: Studies in the Philosophy of Nicholas Maxwell, edited by Leemon

McHenry, Ontos Verlag, Frankfurt, pp. 1-56.

2009b, Are Universities Undergoing an Intellectual Revolution?, Oxford Magazine,

No. 290, Eighth Week, Trinity Term, June, pp. 13-16. , 2010, Cutting God in Half - And Putting the Pieces Together Again: A New

Approach to Philosophy, Pentire Press, London. 2011a, Three Philosophical Problems about Consciousness and their Possible

Resolution, Open Journal of Philosophy, vol. 1, no. 1, pp. 1-10. 2011b, A Priori Conjectural Knowledge in Physics, in What Place for the A Priori?,

edited by Michael Shaffer and Michael Veber, Open Court, Chicago, pp. 211-240. , 2012a, Arguing for Wisdom in the University, Philosophia, vol. 40, no. 4, pp. 6632012b, In Praise of Natural Philosophy: A Revolution for Thought and Life, Philosophia, vol. 40, no. 4, pp. 705-715.

2013a, Has Science Established that the Cosmos is Physically Comprehensible?,

in Travena, A. and Soen, B., (eds.) Recent Advances in Cosmology, Nova Science

Publishers Inc., New York.

Magazine. 2013b, Does Philosophy Betray Both Reason and Humanity?, Philosophers'

2014a, How Universities Can Help Create a Wiser World: The Urgent Need for an Academic Revolution, Imprint Academic, Exeter. 2014b, What's Wrong with Science and Technology Studies? What Needs to Be

Done to Put It Right?, in R. Pisano and D. Capecchi, eds, Physics, Astronomy and Engineering: A Bridge between Conceptual Frameworks, Society and Technologies, Springer, Dordrecht.

, 2014c, What Philosophy Ought to Be, in C. Tandy, ed., Death And Anti-Death,

Volume 11: Ten Years After Donald Davidson (1917-2003), Ria University Press, Palo

Alto, California.

Nagel, T., 1974, 'What Is It Like to Be a Bat?', The Philosophical Review 83, pp. 435-50.

Popper, K., 1969, The Open Society and Its Enemies, Routledge and Kegan Paul, London.

Smart, J.J.C., 1963, Philosophy and Scientific Realism, Routledge and Kegan Paul, London. 